as age, gender, disease duration and hand dominance, were homogeneous at the beginning of the study. In both groups there was a reduction in hand pain with time (intragroup analysis). Pain in the functional group, expressed as mean \pm standard deviation, was $6.82 \pm 1.72$ and $4.77 \pm 2.45$ at the beginning and end of the treatment, respectively, and the corresponding figures for the nighttime group were $7.20 \pm 1.63$ and $4.83 \pm 2.68$. The $p$ values for both groups were $p<0.001$. There were no statistically significant differences in the majority of the parameters assessed between the groups, including the outcome pain. Three measures considered to be occasional, presented a significant difference between the groups: right palmar abduction $p=0.023$ and right tripod pinch strength $p=0.006$ with better results for the group that used the night splint; and time execution of the pick-up test with eyes closed to the right hand $p=0.048$ with more representative results for the functional (daytime) splint use.

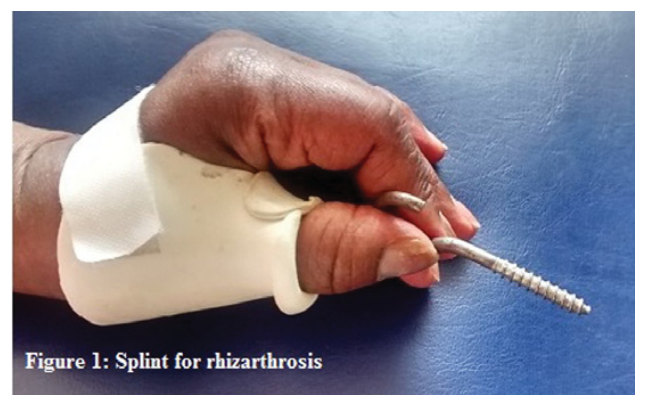

Conclusions: There was no statistically significant difference between functional and night splint in terms of pain, function or any of the other parameters assessed in rhizarthrosis patients after one year of treatment.

References:

[1] Carreira ACG, Jones A, Natour J. Assessment of the effectiveness of a functional splint for osteoarthritis of the trapeziometacarpal joint of the dominant hand: a randomized controlled study. J Rehabil Med 2010;42(5): 469- 74;

[2] Rannou F, Dimet J, Boutron I, et al. Splint for Base-of-Thumb Osteoarthritis. A randomized trial. Annals of Internal Medicine 2009;150(10):661-9; osteoarthritis: systematic review and meta-analysis. Disabil. Rehabil, Early Online 2015: $1-19$.

Disclosure of Interest: None declared

DOI: 10.1136/annrheumdis-2017-eular.5590

\section{THU0729-HPR PATIENTS AND CAREGIVERS PREFERENCES RELATED WITH THE USE OF INFORMATIC TECHNOLOGY TOOLS FOR EDUCATION IN RHEUMATOID ARTHRITIS}

S. Henao ${ }^{1}$, F. Rodriguez ${ }^{2}$, L. Villarreal ${ }^{3}$, P. Santos-Moreno ${ }^{4}$, M. Cabrera ${ }^{5}$, D. Buitrago-Garcia ${ }^{6}$, C. Caicedo ${ }^{7}$. ${ }^{1}$ Patient service; ${ }^{2}$ Patient Program; ${ }^{3}$ Psychology and processes; ${ }^{4}$ Rheumatology; ${ }^{5}$ Engineer and processes;

${ }^{6}$ Epidemiology, Biomab, Center for Rheumatoid Arthritis, Bogota; ${ }^{7}$ Public Health, Universidad Nacional de Colombia, Bogota, Colombia

Background: Rheumatoid arthritis (RA) is a chronic inflammatory disease of the joints affecting more than $1 \%$ of global population, it is a long term condition that causes pain, disability and affects the quality of life (1). It has been demonstrated that patient's involvement with its treatment and disease management can be more effective than information-only given by the physician or a health care professional (2).

Objectives: To describe patient's preferences regarding information technology tools for education and RA management in a specialized center in Bogotá Colombia.

Methods: We conducted a descriptive study where a survey was applied to a group of patients or care-givers attending to a patient-focused symposium in Bogotá Colombia. Descriptive epidemiology was done; percentages and averages were calculated for qualitative variables.

Results: We included 452 participants, $80 \%$ were patients and $20 \%$ caregivers, only $25 \%$ referred to assist to informative activities regarding disease management, $41 \%$ reported to have information regarding $\mathrm{RA}$, also between $29 \%$ and $45 \%$ of patients acknowledged the role of the health-care team in the disease activity management. Regarding technology information tools patients considered that WhatsApp was the most important tool to received messages to disease management $(40 \%)$ followed by YouTube and websites. $70 \%$ reported to have a computer or a mobile phone with internet connection, $60 \%$ reported to use Facebook while only $30 \%$ reported to use easily websites and twitter.

Conclusions: It is important to know the preferences and access that patients and caregivers have to informatics technology in order to create self-care programs that really are going to be used in this population. This survey is evidence not only to start an educational program in our specialized center but to the health care professionals and stakeholders in Colombia.

References:

[1] Prothero L, Georgopoulou S, de Souza S. Patient involvement in the development of a handbook for moderate rheumatoid arthritis. 2016.
[2] Vermaak V, Briffa NK, Langlands B, Inderjeeth C, McQuade J. Evaluation of a disease specific rheumatoid arthritis self-management education program, a single group repeated measures study. BMC musculoskeletal disorders. 2015;16:214.

Disclosure of Interest: None declared

DOI: 10.1136/annrheumdis-2017-eular.5450

\section{THU0730-HPR CONTENT AND SUPERVISION OF GROUP EXERCISE THERAPY (GET) FOR AXIAL SPONDYLOARTHRITIS (AXSPA) IN THE NETHERLANDS; A NATION WIDE SURVEY}

F. Van Der Giesen ${ }^{1,2}$, S. Van Weely ${ }^{2}$, N. Lopuhaa ${ }^{3}$, T. Vliet Vlieland ${ }^{2}$.

${ }^{1}$ Rheumatology, Haga Teaching Hospital, The Hague; ${ }^{2}$ Orthopedics, Leiden University Medical Center, Leiden; ${ }^{3}$ Dutch Arthritis Foundation, Amsterdam, Netherlands

Background: For axSpA patients exercise therapy is recommended in (inter)national treatment guidelines. Apart from mobility exercises, muscle strengthening and cardio vascular training are recommended therapeutic modalities $[1,2]$. In the Netherlands 45 therapy groups (land based exercises; 1, hydrotherapy; 13 , combination groups; 31 ) are organized by 17 local patient organizations exclusively for AxSpA patients. It is unclear if the treatment recommendations are followed and what the nature of the supervision in these exercise programs is. Objectives: To describe the therapeutic modalities used and characteristics of the supervision in GET for patients with axSpA in the Netherlands.

Methods: A questionnaire was sent to the coordinating supervisors of GET from the17 local patient organisations involved in GET for axSpA with questions regarding the frequency and duration of group exercise programs and treatment modalities (mobility, stregthening and/or cardio-vascular exercises) used in landbased and hydrotherapy parts of the programs. In addition the questionnaire included questions regarding the number of supervisors involved in the supervision of GET, their professional background (physical therapist, other), years of experience with GET ( $<1 \mathrm{yr}, 1-5 \mathrm{yrs},>5 \mathrm{yrs}$ ) additional education related to rheumatic diseases (yes/no) and rheumatology network membership (yes/no).

Results: All 17 coordinating supervisors of GET for axSpA returned the questionnaire. All exercise groups were performed once a week with a median (range) duration of 30 minutes (30-60) for the hydrotherapy and 105 minutes (45-180) for the combination therapy groups. Regarding land-based treatment modalities, active joint range of motion exercises and muscle strengthening exercises were used as stated by $15 / 17$ and 14/16 coordinators respectively. In hydrotherapy this was $17 / 17$ both. $13 / 16$ coordinators stated that cardio-vascular training was used in land-based parts and in hydrotherapy parts in 14/17. Only $1 / 17$ coordinator stated that hart rate monitoring (land-based) was used. A total of 64 supervisors were involved in GET for axSpA of whom 54/60 were physical therapists. $35 / 59$ were involved for more than 5 years, $21 / 55$ had post graduate rheumatology education and 10/54 were rheumatology network members.

Conclusions: Mobility and strengthening exercises are used in the majority of GET programs, but hart rate monitoring is almost never used raising questions regarding the intensity of these programs. The duration of exercise sessions showed a wide variety, as did the program composition (water based/land and water based) identifying considerable practice variation. The majority of the supervisors were physical therapists with long standing experience but only a minority had postgraduate rheumatology education. To ensure the quality of GET for patients with axSpA, reducing practice variation is a future challenge. Education of GET supervisors might be important aspects and target of priority.

\section{References:}

[1] Van der Heijde D, Ramiro S, et al. 2016 update of the ASAS-EULAR management recommendations for axial spondyloarthritis. Annals of the rheumatic diseases. 2017.

[2] Dutch Arthritis Association, Guidelines for diagnostics and treatment in axial spondylitis. 2014.

Acknowledgements: This study was funded by the Dutch Arthritis Foundation.

Disclosure of Interest: None declared

DOI: 10.1136/annrheumdis-2017-eular.4192

\section{THU0731-HPR CAN A THREE WEEKS PROGRAM IN A REHABILITATION CENTER IMPROVE SYMPTOMS AND EXERCISE-FREQUENCY FOR RHEUMATIC PATIENTS?}

G. Jarret, A. Orpana. Skogli Helse- og Rehabiliteringsenter AS, Lillehammer, Norway

Background: Rehabilitation for people with rheumatic disorders (15\% of worldwide population) is a long term project (Stoffer et al. 2015). Rheumatic patients do not exercise as often as recommended (Holm et al. 2015). Intensive multidisciplinary interventions in rehabilitation-centers are in some countries an optionof which there is little effect knowledge. Perhaps data from a quality-management report can shed some preliminary light on this subject.

Objectives: Primarily to observe short and long term effects of a three weeks intensive multidisciplinary program for people with rheumatic disorders, and secondary to see if a correlation can be found between level of training frequency and levels of pain, stiffness, and self rated health. 